\title{
Effects of the p16/cyclin D1/CDK4/Rb/E2F1 pathway on aberrant lung fibroblast proliferation in neonatal rats exposed to hyperoxia
}

\author{
SHIMENG ZHAO, ZHIGUANG CHEN, SHUANG HAN and HONGMIN WU \\ Department of Neonatology, The First Affiliated Hospital of China Medical University, \\ Shenyang, Liaoning 110001, P.R. China
}

Received August 10, 2020; Accepted March 11, 2021

DOI: $10.3892 /$ etm.2021.10491

\begin{abstract}
INK4a }}$ (p16) inhibits the vital $\mathrm{G}_{1}$ to $\mathrm{S}$ phase transition during cell cycle progression through the p16/cyclin D1/CDK4/retinoblastoma(Rb)/E2F1 pathway. Hyperoxia can suppress the $G_{1} / S$ checkpoint and induce more lung fibroblasts (LFs) to transition from the $\mathrm{G}_{1}$ phase to the $S$ phase and undergo cell proliferation. The present study investigated the rate of 16 gene promoter methylation and the protein expression levels of p16, cyclin D1, CDK4, Rb and E2F1 in LFs from the lungs of rats exposed to hyperoxia and normoxia on postnatal days 3,7 and 14. In the hyperoxia-exposed group, the methylation rate was 50 and $80 \%$ on days 7 and 14, respectively. Cyclin D1 and CDK4 overexpression was associated with p16 loss and Rb inactivation by phosphorylation. Rb phosphorylation induced E2F1 release in the $\mathrm{G}_{1}$ phase, which promoted cell proliferation. No methylation was observed in the normoxia-exposed group. These observations suggested that p16 loss may stimulate aberrant LF proliferation via the p16/cyclin D1/CDK4/Rb/E2F1 pathway.
\end{abstract}

\section{Introduction}

Premature infants with respiratory disorders usually require inhalation of high levels of oxygen. Prolonged exposure to high levels of oxygen may lead to lung injury, which often results in widespread lung fibrosis (1). The main manifestation of lung fibrosis is the uncontrolled proliferation of lung fibroblasts (LFs) that are deposited in the pulmonary interstitial space or replace the normal lung epithelium (2). The hyperplasia and replacement of fibrous tissue after tissue injury are noteworthy pathophysiological processes of tissue repair. Discovering how to effectively prevent LF proliferation in order to alleviate lung

Correspondence to: Dr Shimeng Zhao, Department of Neonatology, The First Affiliated Hospital of China Medical University, 155 Nan Jing Northern Street, Shenyang, Liaoning 110001, P.R. China E-mail: zsm725@163.com

Key words: hyperoxia, lung fibroblasts, p16/CDK4/Rb/E2F1, cell proliferation fibrosis without affecting tissue repair is the key to curing. To address this problem, the mechanism that regulates the cell cycle during LF proliferation needs to be clarified.

A cell divides into two identical cells through the precisely controlled $\mathrm{G}_{1}, \mathrm{~S}, \mathrm{G}_{2}$ and $\mathrm{M}$ phases of the cell cycle. During cell cycle progression, cells that pass the $G_{1} / S$ checkpoint of the cycle, characterized by the initiation of DNA synthesis, are committed to dividing into two complete cells (3). The p16 ${ }^{\text {INK4a }}(\mathrm{p} 16) /$ cyclin D/CDK4/retinoblastoma-associated protein $(\mathrm{Rb}) / \mathrm{E} 2 \mathrm{~F} 1$ pathway is recognized as a key pathway in the regulation of cell proliferation, for which E2F1 is a notable downstream effector. Deregulated E2F1 activity due to the aberrance of the upstream components in this pathway, such as inactivation of p16, confers a growth advantage to cells (4-7). During the $G_{1}$ phase of the normal cell cycle, Rb is inactivated by sequential phosphorylation events that are mediated by various cyclin-dependent kinases (CDKs), leading to the release of E2F transcription factors, the activation of numerous genes (such as p19ARF and p53 et al) and cell cycle progression (8). p16 is a cyclin-dependent kinase inhibitor that positively regulates the expression of cyclin D1 at the post-transcriptional level. p16 and cyclin D1 competitively bind to CDK4 to prevent cells from entering the corresponding phase of the cell cycle and, therefore, inhibit its protein kinase activity. This inhibition suppresses the CDK4-mediated phosphorylation of the $\mathrm{Rb}$ protein. When phosphorylated (p)-Rb binds to E2F1 to form a complex, the transcriptional activation of E2F1 is inhibited, thereby preventing the cell from transitioning from the $G_{1}$ to the $\mathrm{S}$ phase and inhibiting cell proliferation $(6,9)$. Therefore, together, p16, CDK4, Rb and E2F1 constitute a feedback loop that directly regulates the cell proliferation cycle. Once the p16 gene is mutated, transduction through the loop is unable to proceed.

Our previous study found that LFs isolated from rats exposed to hyperoxia in vivo showed significantly greater proliferation compared with those from rats exposed to normoxia. In addition, using flow cytometry, it was revealed that the percentage of LFs in the $S$ and $G_{2} / M$ phases increased, and the proportion of LFs in the $G_{0} / G_{1}$ phase decreased simultaneously (10). In another study, we confirmed that 5-aza-2'-deoxycytidine, a DNA methylation inhibitor, inhibited hyperoxia-induced LF proliferation by restoring p16 expression (11). However, the underlying mechanism has not been investigated and the results from previous studies are 
incomplete. In the present study, the protein expression of p16, cyclin D1, CDK4, Rb and E2F1 was measured in LFs from rats exposed to hyperoxia or normoxia to further understand the occurrence and development of the aberrant LF proliferation induced by hyperoxia.

\section{Materials and methods}

Animals and oxygen exposure. The present study was approved by The China Medical University Animal Research Committee (Shenyang, China; approval no. 2017PS140K). Healthy Sprague-Dawley rats ( $\mathrm{n}=40$; female:male, 4:1) obtained from The Center of Animal Experiments, China Medical University, were used for this experiment. The higher the concentration of oxygen inhaled, the more obvious the changes in lung fibrosis. A fraction of inspired oxygen $\left(\mathrm{FiO}_{2}\right)>85 \%$ (the lethal oxygen concentration) is frequently employed in experimental studies (12-14). In the present study, the newborn rats $(<12$-h old) were randomly divided into the normoxia $\left(\mathrm{FiO}_{2}, 21 \%\right)$ or hyperoxia $\left(\mathrm{FiO}_{2}, 90 \pm 2 \%\right)$ groups The hyperoxia group was monitored twice daily (MT-01 Gas Monitor). $\mathrm{CO}_{2}$ was absorbed by soda lime to maintain a concentration of $<0.5 \%$. The average birth weight of the rats was $5.12 \pm 0.26 \mathrm{~g}$ in the hyperoxia group and $4.98 \pm 0.19 \mathrm{~g}$ in the normoxia group. No statistically significant difference was observed. Within $12 \mathrm{~h}$ of birth, the newborn rats (with the mother rats) were housed in standard cages placed inside 425-1 capacity plexiglass isolation chambers that received humidified $\mathrm{O}_{2}$ or room air $(301 / \mathrm{min})$ at ambient pressure for up to 14 days. Each rat was fed at $20-26^{\circ} \mathrm{C}$ and $12 \mathrm{~h}$ light/dark cycle. The cages were opened for $0.5 \mathrm{~h}$ every day to add standard laboratory food and water and change the padding. To avoid oxygen toxicity, the mother rats were rotated between the normoxia and hyperoxia environments every day.

Histological examination. On postnatal days 3, 7 and 14,5 pup rats in each group were sacrificed with an intraperitoneal injection of pentobarbital sodium $(100 \mathrm{mg} / \mathrm{kg})$ and were exsanguinated by aortic transection. Right lung tissue samples were washed with PBS, placed in $4 \%$ paraformaldehyde at room temperature for $24 \mathrm{~h}$, then serially dehydrated with increasing concentrations of ethanol before being embedded in paraffin. The paraffin-embedded lung tissue samples were cut into $4-\mu \mathrm{m}$ sections, stained with hematoxylin and eosin (H\&E; for $5 \mathrm{~min}$ ) and Masson's trichrome staining (Weigert's iron hematoxylin solution for $3 \mathrm{~min}$, Ponceau xylidine and fuchsin $\mathrm{S}$ solution for $30 \mathrm{~min}$ ) at room temperature, examined using light microscopy and assessed for the presence of intra-alveolar edema, inflammatory cell infiltration and fibrosis.

Primary culture of LFs. The rats in both the hyperoxia and normoxia groups were euthanized on postnatal days 3, 7 and 14 . The left lungs were quickly removed from the chest, minced into $1-\mathrm{mm}^{3}$ pieces and digested in $0.2 \%$ trypsin and $0.016 \%$ deoxyribonuclease I in minimum essential medium (MEM; Beijing Solarbio Science \& Technology Co., Ltd.) for $2-4 \mathrm{~h}$ at $37^{\circ} \mathrm{C}$ in a shaking water bath. Next, $10 \% \mathrm{FBS}$ (Clark Bioscience) was added to the filtered cell suspensions to stop further digestion. The harvested cells were obtained by centrifugation at $400 \mathrm{x}$ for $3 \mathrm{~min}$ at $4^{\circ} \mathrm{C}$, and then cultured in air and $5 \% \mathrm{CO}_{2}$ at $37^{\circ} \mathrm{C}$ in MEM with $10 \% \mathrm{FBS}$, $10,000 \mathrm{U} / \mathrm{ml}$ penicillin and $10,000 \mu \mathrm{g} / \mathrm{ml}$ streptomycin for $72 \mathrm{~h}$. The LF purity was confirmed at $>95 \%$ by immunocytochemical staining for vimentin. Briefly, cultured LFs were fixed in $4 \%$ paraformaldehyde for $30 \mathrm{~min}$ at $37^{\circ} \mathrm{C}$. Next, a primary antibody against vimentin (1:100; cat. no. sc-5565; Santa Cruz Biotechnology, Inc.) was added to the cells and incubated overnight at $4^{\circ} \mathrm{C}$. Then, cells were stained with goat anti-rat secondary antibody (1:100; Beijing Zhongshan Golden Bridge Biotechnology Co., Ltd.) for $30 \mathrm{~min}$ at $37^{\circ} \mathrm{C}$. When passaged, the cells were seeded into $150-\mathrm{cm}^{2}$ culture flasks at a density of $2.5 \times 10^{5}$ or $5 \times 10^{5}$ cells/flask. All the experiments were performed using fibroblasts from passage number two.

MTT assay. A 3-(4,5-dimethy-lthiazol-2-yl)-2,5-diphenyltetrazolium (MTT) assay was performed for cell proliferation. Cells were seeded into 96 -well plates at a density of $5 \times 10^{4}$ cells per well and cultured at $37^{\circ} \mathrm{C}$ in air and $5 \% \mathrm{CO}_{2}$ for $24 \mathrm{~h}$. Next, $20 \mu \mathrm{l}$ of $5 \mathrm{mg} / \mathrm{ml}$ MTT (Sigma-Aldrich; Merck KGaA) was added into each well and the cells were cultured for an additional $4 \mathrm{~h}$ at $37^{\circ} \mathrm{C}$. After culture, the supernatant was discarded and the resulting formazan crystals were solubilized by adding $150 \mu \mathrm{l}$ of DMSO to each well. The optical density level was measured at a wavelength of $570 \mathrm{~nm}$. Experiments were performed in quintuplicate.

Methylation-specific polymerase chain reaction (MSP). LFs from the hyperoxia and normoxia groups were collected at $120 \mathrm{~h}$ post-incubation in MEM with $10 \%$ FBS. A ZR-96 Quick-gDNA $^{\mathrm{TM}}$ kit (Zymo Research Corp.) was used to extract the DNA as recommended by the manufacturer. An EZ DNA Methylation-Gold ${ }^{\mathrm{TM}}$ kit (Zymo Research Corp.) was used to perform the bisulfite modification of the genomic DNA according to the manufacturer's instructions. PCR amplification was performed using p16 promoter gene fragment-specific primers for methylated or unmethylated DNA (Sangon Biotech Co., Ltd.). The primers used to amplify unmethylated p16 were as follows: Sense, 5'-TTTTTGGTG TTAAAGGGTGGTGTACT-3' and antisense, 5'-CACAAA AACCCTCACTCACAACAA-3', which yielded a 132-bp fragment. The primers used to amplify methylated p16 were as follows: Sense, 5'-GTGTTAAAGGGCGGCGTAGC-3' and antisense, 5'-AAAACCCTCACTCGCGACGA-3', which yielded a PCR product of $122 \mathrm{bp}$. PCR was performed under the following conditions: $95^{\circ} \mathrm{C}$ for $4 \mathrm{~min}$, followed by 25 cycles of $94^{\circ} \mathrm{C}$ for $25 \mathrm{sec}, 62^{\circ} \mathrm{C}$ for $25 \mathrm{sec}$ and $72^{\circ} \mathrm{C}$ for $30 \mathrm{sec}$, and a final extension at $72^{\circ} \mathrm{C}$ for $5 \mathrm{~min}$. CpGenome universal methylated DNA (EMD Millipore; Merck KGaA) was used as the control for methylated DNA. The PCR-amplified products were separated by electrophoresis on a $2 \%$ agarose gel and visualized using ethidium bromide staining for 20 min under ultraviolet light. Images were then captured and the DNA methylation of p16 was determined by MSP as previously described (15).

Western blotting. Western blotting was performed as previously described (7). The following specific primary antibodies were used: Anti-cyclin D1 (cat. no. SC-450; 1:500), anti-CDK6 (cat. no. SC-7961; 1:500), anti-p16 (cat. no. sc-74400; 1:400), anti-Rb (cat. no. sc-102; 1:500) and 
A
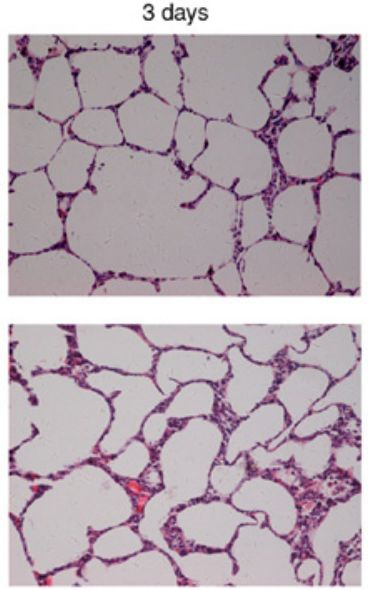

B
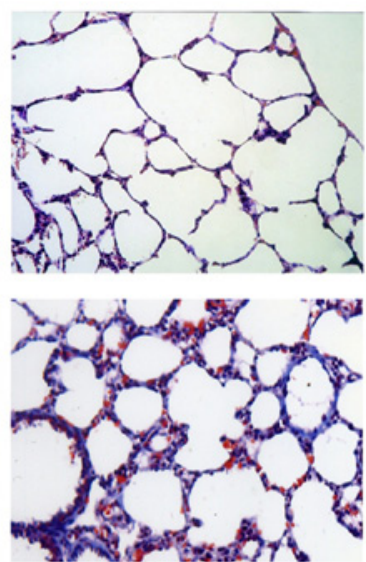

7 days
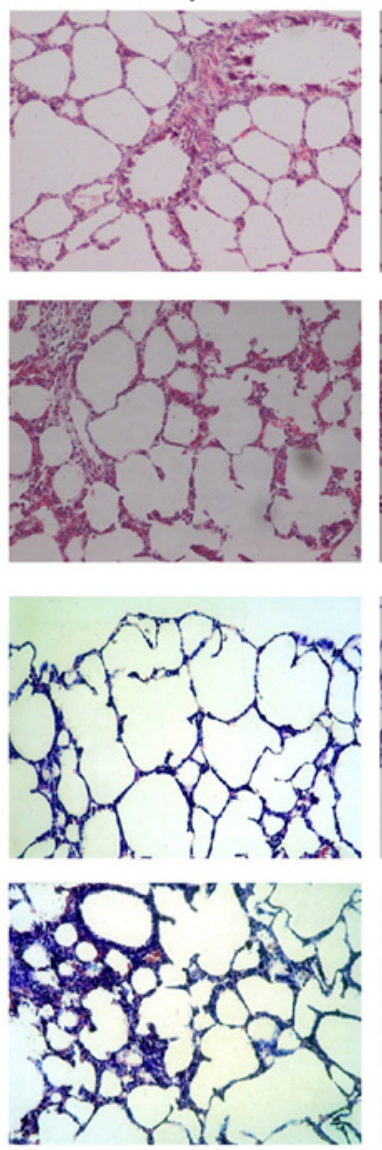

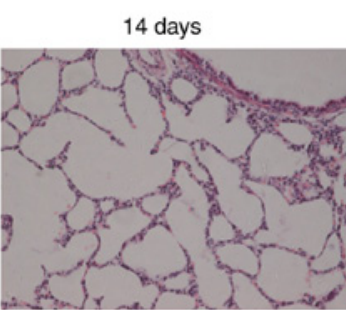

Normoxia

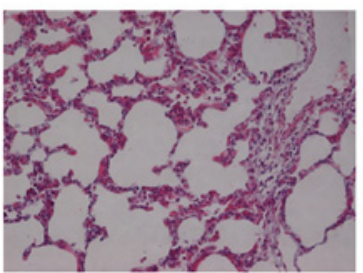

Hyperoxia
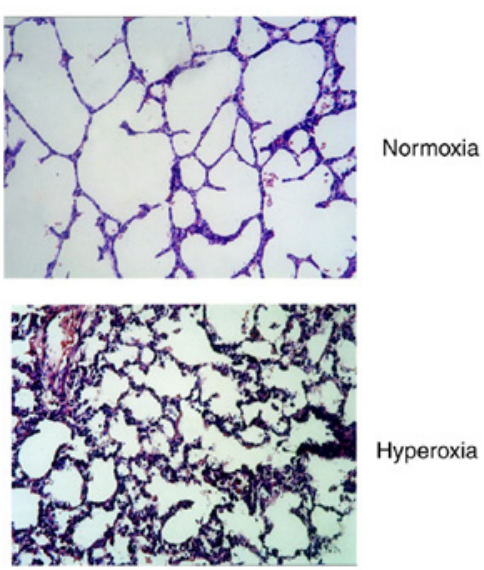

Figure 1. Histological examination of normoxia- and hyperoxia-exposed lung tissues. (A) Hematoxylin-eosin and (B) Masson's trichrome staining (magnification, $\mathrm{x} 200$ ).

anti-p-Rb (cat. nos. ser-795 and sc-21875; 1:200) obtained from Santa Cruz Biotechnology, Inc. An anti-CDK4 antibody (cat. no. 12790S; 1:1,000) was obtained from Cell Signaling Technology, Inc. A $\beta$-actin antibody was obtained (cat. no. A-3853 Sigma-Aldrich; Merck KGaA) and used at a 1:1,000 dilution. The proteins in the membrane were detected using an enhanced chemiluminescence system (ECL Advance; Amersham Biosciences; Cytiva) and images were captured and analyzed using a BioRad ChemiDoc XRS system (BioRad Laboratories, Inc.).

Statistical analysis. The values are expressed as the mean \pm standard deviation. SPSS software (v17.0; SPSS, Inc.) was used for the statistical analyses. The statistical significance of the differences was analyzed using an unpaired two-tailed $\mathrm{t}$-test for comparison between two groups. $\mathrm{P}<0.05$ was considered to indicate a statistically significant difference.

\section{Results}

Effect of hyperoxia on lung histology and morphometrics. Normal structure and alveolarization were observed in the normoxia group on postnatal days 3, 7 and 14. No obvious differences in pathology were observed between the groups on postnatal day 3. Hyperoxia treatment induced the development of a disordered lung tissue structure, alveolar collapse, obvious alveolar wall thickening and numerous blue-stained stripes and flakes, indicating collagen deposition, and these changes were present on postnatal day 7 and increased over time through postnatal day 14 (Fig. 1).

Effect of hyperoxia on cell proliferation. As seen in Fig. 2, the LFs isolated from the rats exposed to hyperoxia in vivo showed significantly greater proliferation compared with the LFs isolated from normoxia-exposed animals on postnatal day 7 and $14(\mathrm{P}<0.05$ and $\mathrm{P}<0.01$, respectively).

Effect of hyperoxia on p16 methylation rate and pl6 protein expression. No methylation was observed in any of the normoxia-exposed groups (postnatal days 3, 7 and 14). In the hyperoxia-exposed group, the rate of p16 promoter methylation on day 7 was $50 \%(n=10$; the complete methylation rate was $30 \%$ and the partial methylation rate was $20 \%$ ). The rate of 16 promoter methylation on day 14 was $80 \%(n=10$; the complete methylation rate was $70 \%$ and the partial methylation rate was $10 \%$ ). No methylation was observed on day 3 in the hyperoxia-exposed group (Fig. 3).

The newborn rats that were exposed to hyperoxia displayed lower protein expression levels of p16 in LFs on postnatal days 7 and 14 compared with the newborn rats that were exposed to normoxia $(\mathrm{P}<0.01$; Fig. 4). No statistically significant differences were found in the LFs in the two groups 


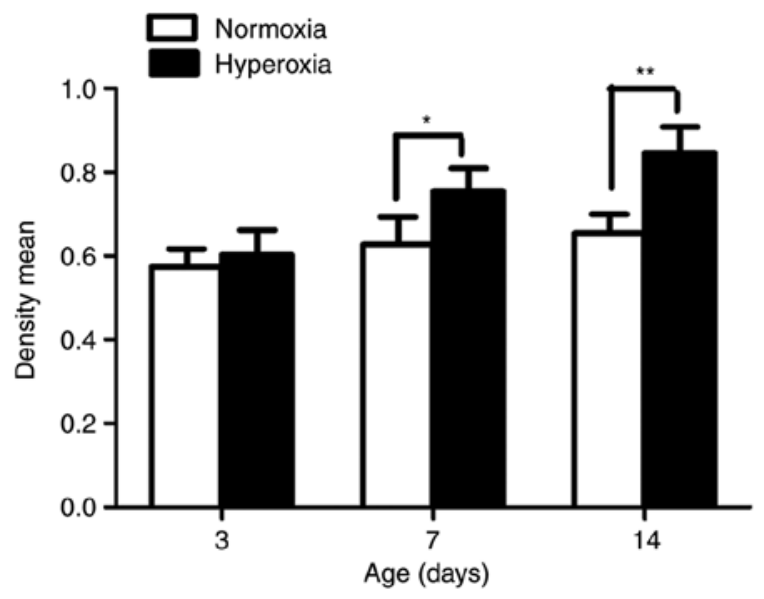

Figure 2. Effect of hyperoxia on cell proliferation on postnatal days 3, 7 and 14. $\mathrm{n}=5$ for each experimental group. ${ }^{*} \mathrm{P}<0.05$ and ${ }^{* *} \mathrm{P}<0.01$. OD, optical density.

on day 3. These results suggest that the hyperoxia-induced p16 gene promoter hypermethylation in the LFs may have suppressed or blocked the protein expression of p16.

Effect of hyperoxia on cyclin D1, CDK4 and CDK6 protein expression. By controlling cell proliferation in the $\mathrm{G}_{1}$ phase, p16 inhibits the ability of the cyclin D/CDK4 complex to phosphorylate $\mathrm{p}-\mathrm{Rb}$. Therefore, p16 loss is correlated with cyclin D1 upregulation. Protein levels of cyclin D1 and CDK4 were examined in cultured lung cells in the present study. On postnatal day 3, no statistically significant difference was observed between the cyclin D1 and CDK4 protein expression levels in the LFs in the two groups (Fig. 5). The cyclin D1 and CDK4 protein expression levels were significantly greater in the hyperoxia-exposed group compared with those in the normoxia-exposed group on postnatal days 7 and 14 (all $\mathrm{P}<0.01$; Fig. 5B and C). However, no statistically significant difference was found in CDK6 protein expression between the two groups at the different time points ( $P>0.05$; Fig. 5D).

Effect of hyperoxia on $R b, p-R b$ and E2F1 protein expression. In the present study, no statistically significant difference was found in $\mathrm{Rb}$ protein expression between the two groups at the different time points (days 3,7 and 14). $\mathrm{p}-\mathrm{Rb} / \mathrm{Rb}$ ratio and $\mathrm{E} 2 \mathrm{~F} 1$ protein expression were significantly greater in the hyperoxia-exposed group compared with that in the normoxia-exposed group on postnatal days 7 and $14(\mathrm{P}<0.05$ and $\mathrm{P}<0.01$, respectively; Fig. 6B and $\mathrm{C}$ ).

\section{Discussion}

Excessive LF proliferation is a key process in pulmonary fibrosis, and abnormal regulation of the cell cycle at the $G_{1} / S$ phase is necessary for hyperoxia-induced LF overproliferation (10). Our previous study found that exposure to hyperoxia weakened the $\mathrm{G}_{1} / \mathrm{S}$ checkpoint, enabling more LFs to pass this checkpoint and progress from the $G_{1}$ phase to the $\mathrm{S}$ and $\mathrm{G}_{2} / \mathrm{M}$ phases to complete DNA replication; this phenomenon promotes eventual LF division and proliferation (10). In the transition from the $G_{1}$ phase to the $S$

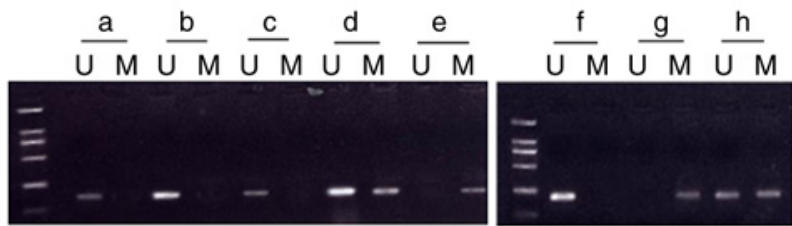

Figure 3. Methylation state of the p16 gene in lung fibroblasts. (a) Normoxia and (b) hyperoxia on postnatal day 3. (c) Normoxia and (d and e) hyperoxia on postnatal day 7. (f) Normoxia and ( $g$ and $h$ ) hyperoxia on postnatal day 14 . U, unmethylated; M, methylated.

phase, the activity of cyclin D1-CDK4/6 plays a decisive role. Once activated, the $\mathrm{Rb}$ protein is phosphorylated by cyclin D1-CDK4 to become p-Rb, which releases sequestered E2F transcription factors, thereby promoting the transcription of genes required for cell cycle progression (16). Cell cycle progression is under the control of CDK inhibitors, such as p16, that competitively bind to CDK4/6 kinases and prevent them from binding to their regulator cyclin D1; this blocks $\mathrm{Rb}$ protein phosphorylation, which sequesters the E2F transcription factors that control the transcription of S-phase genes (17). Therefore, the p16/cyclin D/CDK4/Rb/E2F pathway is a critical regulator of the important $\mathrm{G}_{1}$ phase to $\mathrm{S}$ phase transition of the cell cycle (18-20).

Yue et al (21) first showed that the p16 promoter was methylated in the lung tissues of hyperoxia-exposed mice, and that p16 promoter methylation increased as the duration of hyperoxia exposure increased. We previously repeated this experiment at the cellular level and reached the same conclusion, namely, that exposure to hyperoxia inhibited p16 gene expression in LFs and that high levels of p16 methylation in the promoter region may be the main cause of p16 transcriptional inactivation (11). The loss of p16 function may promote cellular proliferation and impair cell cycle arrest or senescence, allowing the survival of genetically damaged cells (22). The p16 protein acts as a cell proliferation inhibitor by competitively binding to CDK4/6 kinases, which prevents them from binding to their regulator cyclin D1 and blocks Rb protein phosphorylation, thus leading to cell cycle arrest (23). The loss of p16 during $\mathrm{G}_{1} / \mathrm{S}$ phase cell cycle regulation is closely associated with the upregulation of cyclin D1 and CDK4, which act synergistically with p16 loss to subvert the control of the $G_{1}$ phase in Rb-positive normal cells $(24,25)$.

In the present study, cyclin D1 and CDK4 were expressed at significantly higher levels in the LFs of hyperoxia-exposed rats compared with the levels in the LFs from normoxia-exposed rats on postnatal days 7 and 14. However, no statistically significant difference was observed in CDK6 protein expression between the two groups at the different time points. This finding indicated that the loss of p16 expression was an early event in abnormal LF proliferation that activated the cyclin D1-CDK4 complex. The Rb protein was phosphorylated by the cyclin D1-CDK4 complex to become $\mathrm{p}-\mathrm{Rb}$.

$\mathrm{Rb}$ is the link between extracellular signals and nuclear signals (26). Rb exhibits two phosphorylation states. The non-phosphorylated form of Rb is expressed in the $G_{0} / G_{1}$ phase of the cell cycle, and it is phosphorylated in the $S / G_{2}$ phase, which suggests that $\mathrm{Rb}$ is a key regulatory gene (27). In its hypo-phosphorylated form, the $\mathrm{Rb}$ proteins acts as a cell 


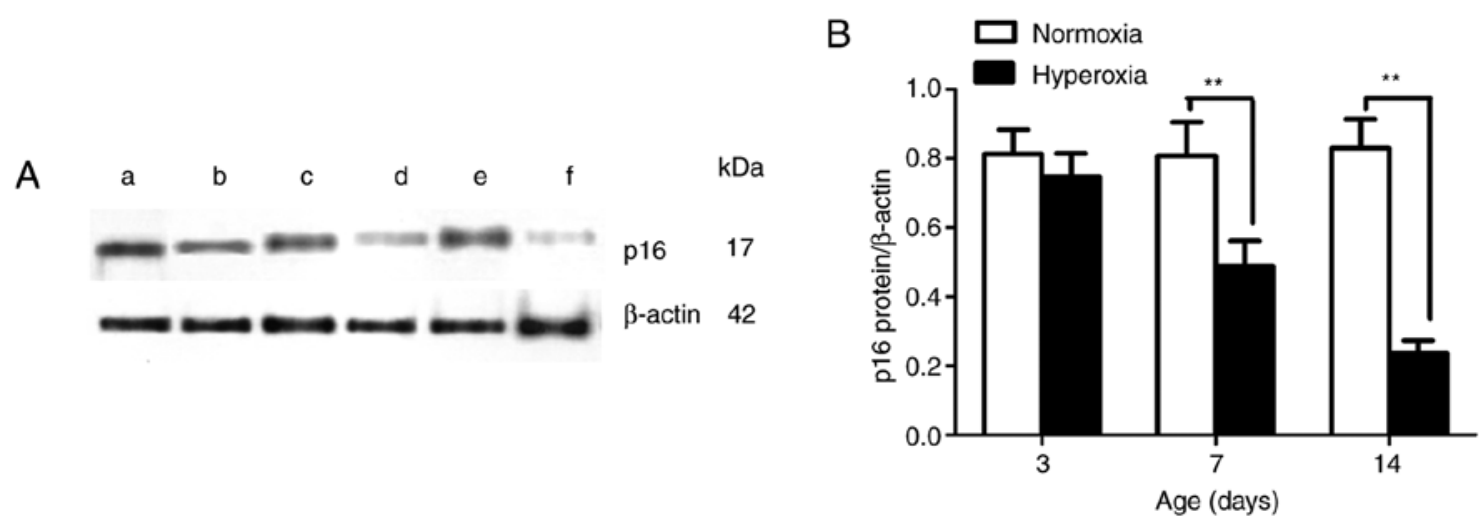

Figure 4. Effect of hyperoxia on p16 expression. (A) Representative protein bands for p16 and loading control $\beta$-actin. (a) Normoxia and (b) hyperoxia on postnatal day 3. (c) Normoxia and (d) hyperoxia on postnatal day 7. (e) Normoxia and (f) hyperoxia on postnatal day 14. (B) p16 protein expression in lung fibroblasts. $\mathrm{n}=5$ for each experiment group. ${ }^{* *} \mathrm{P}<0.01$. p16, p16INK4a.
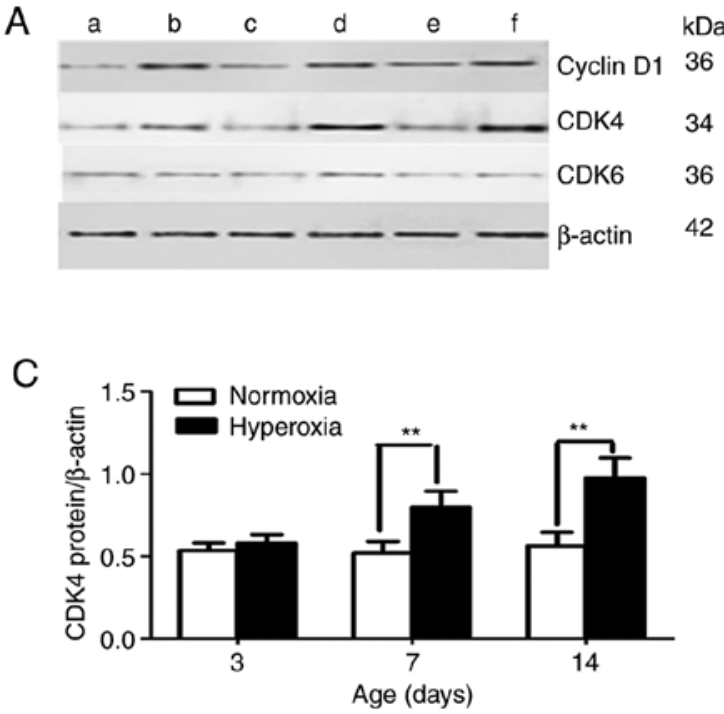

B

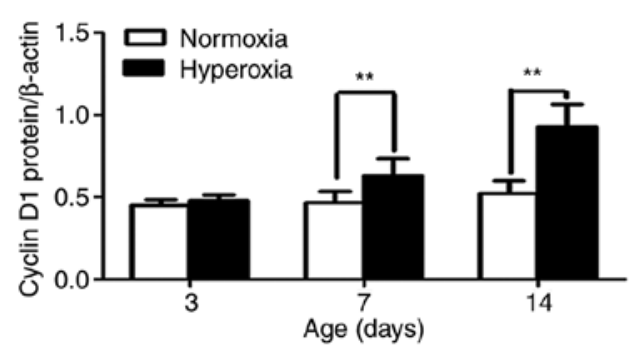

D

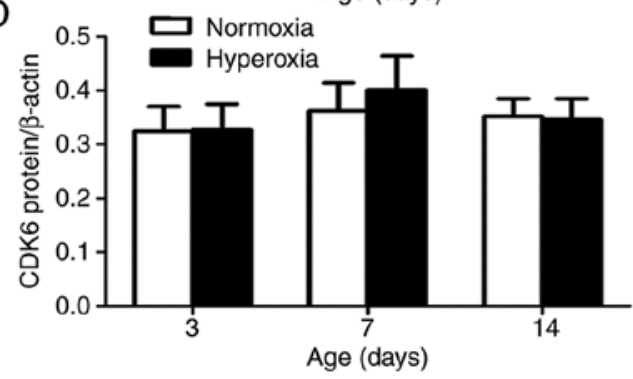

Figure 5. Effect of hyperoxia on cyclin D1 and CDK4 expression. (A) Representative protein bands for cyclin D1, CDK4 and the $\beta$-actin loading control for western blotting. (a) Normoxia and (b) hyperoxia on postnatal day 3. (c) Normoxia and (d) hyperoxia on postnatal day 7. (e) Normoxia and (f) hyperoxia on postnatal day 14. (B) Cyclin D1, (C) CDK4 and (D) CDK6 protein expression in lung fibroblasts. $\mathrm{n}=5$ for each experiment group. ${ }^{* *} \mathrm{P}<0.01$.

cycle regulator to induce $G_{1}$ arrest. Dysfunction of the proteins involved in the p16 pathway, such as p16 gene deletion and cyclin D1 upregulation, leads to Rb phosphorylation, subsequent $G_{1} / S$ phase transition and uncontrolled cell proliferation (28-30).

The present study first determined the overall expression level of $\mathrm{Rb}$ in LFs and found no significant difference between the $\mathrm{Rb}$ expression levels in the hyperoxia-exposed and normoxia-exposed groups. This finding showed that hyperoxia did not change the overall expression level of $\mathrm{Rb}$. The $\mathrm{Rb}$ protein contains 16 cyclin-dependent kinase phosphorylation sites. The functional state of the $\mathrm{Rb}$ protein depends on its phosphorylation at these different sites. Ser-795 phosphorylation indicates that $\mathrm{Rb}$ has transitioned from an active non-phosphorylated state to an inactive phosphorylated state. Ser-795 is phosphorylated by cyclin D1/CDK4, which arrests the Rb-mediated cell cycle (31). The current study next examined the expression levels of $\mathrm{p}-\mathrm{Rb}$ (Ser-795) in LFs and found that the $\mathrm{p}-\mathrm{Rb} / \mathrm{Rb}$ ratio was significantly higher in the hyperoxia-exposed group compared with that in the normoxia-exposed group on postnatal days 7 and 14. This finding indicated that hyperoxia did not change the overall expression levels of $\mathrm{Rb}$ in LFs, but did change its phosphorylation state.

Once $\mathrm{Rb}$ is phosphorylated, it induces the release of E2F in the late $G_{1}$ phase, which in turn enhances the expression of genes that encode the regulatory proteins that are necessary for cell cycle progression (27). E2F family members play a noteworthy role during the $G_{1} / S$ transition in the mammalian cell cycle. The E2F family is generally divided into two groups by function: The transcriptional activators and the transcriptional repressors. Activators such as E2F1, E2F2 and E2F3a promote and help perpetuate the cell cycle, while repressors inhibit the cell cycle (32). E2F1 upregulation stimulates cellular proliferation. In numerous types of human tumors (such as breast cancer, lung tumors, et al), E2F1 overexpression accelerates the transition of cells from the $G_{1}$ phase to the $S$ phase, resulting in excessive cell proliferation, malignant transformation and tumor formation (33-35). In the present study, a high level of E2F1 

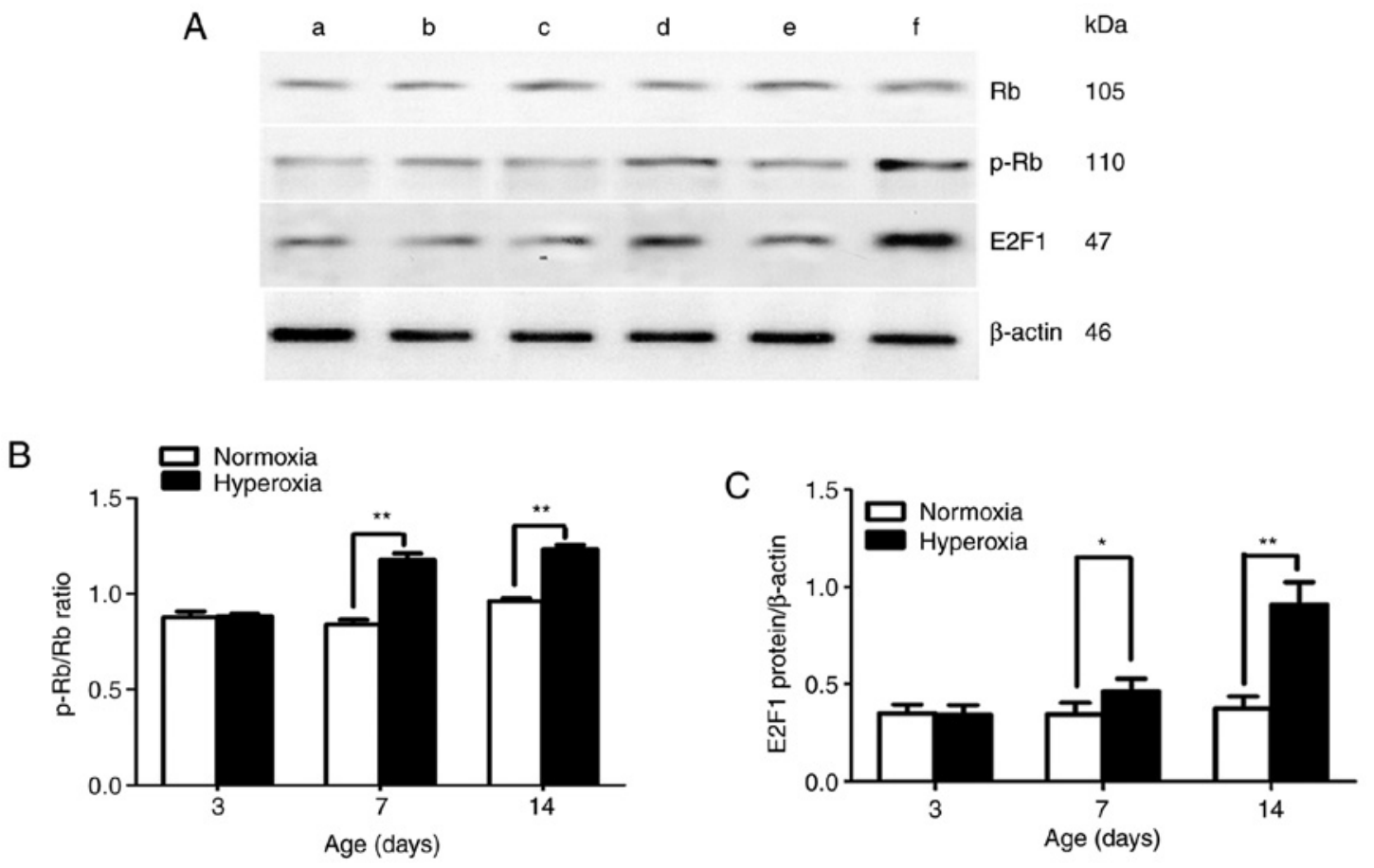

Figure 6. Effect of hyperoxia on Rb, p-Rb and E2F1 expression. (A) Representative protein bands for Rb, p-Rb, E2F1 and the $\beta$-actin loading control. (a) Normoxia and (b) hyperoxia on postnatal day 3. (c) Normoxia and (d) hyperoxia on postnatal day 7. (e) Normoxia and (f) hyperoxia on postnatal day 14. (B) $\mathrm{p}-\mathrm{Rb} / \mathrm{Rb}$ ratio in LFs. (C) E2F1 protein expression in lung fibroblasts. $\mathrm{n}=5$ for each experiment group. ${ }^{*} \mathrm{P}<0.05$ and ${ }^{* *} \mathrm{P}<0.01$. $\mathrm{p}-$, phosphorylated; Rb, retinoblastoma-associated protein.

expression was observed in primary cultured LFs from hyperoxia-exposed rats.

Our previous study determined that the p16 promoter methylation induced by hyperoxia plays a role in the excessive proliferation of LFs (11). The current study found that the loss of p16 expression activated the cyclin D1-CDK4 complex, and that the Rb protein was phosphorylated by cyclin D1-CDK4 to become $\mathrm{p}-\mathrm{Rb}$, after which E2F1 binding on it could be released. E2F1 upregulation accelerated the transition of cells, resulting in excessive LF proliferation. In summary, the disruption of the $\mathrm{p} 16 /$ cyclin $\mathrm{D} / \mathrm{CDK} 4 / \mathrm{Rb} / \mathrm{E} 2 \mathrm{~F} 1$ pathway may play a key role in the aberrant LF proliferation induced by hyperoxia.

\section{Acknowledgements}

The authors would like to thank Dr Xindong Xue (Shengjing Hospital of China Medical University, Shenyang, Liaoning, China) for advice on experimental design and support of the study.

\section{Funding}

No funding was received.

\section{Availability of data and materials}

All datasets used and/or analyzed during the current study are available from the corresponding author on reasonable request.

\section{Authors' contributions}

SZ performed the experiments. ZC and SH collected and analyzed the data. HW designed the study and was the major contributor in writing the manuscript. All authors read and approved the final manuscript. $\mathrm{ZC}$ and $\mathrm{SH}$ confirmed the authenticity of all the raw data.

\section{Ethics approval and consent to participate}

The current study was approved by the Medical Ethics Committee at the China Medical University (grant no. 2017PS140K).

\section{Patient consent for publication}

Not applicable.

\section{Competing interests}

The authors declare that they have no competing interests.

\section{References}

1. Chen CM: Therapy for neonatal hyperoxia-induced lung injury. Pediatr Neonatol 55: 329-330, 2014.

2. Crapo JD, Barry BE, Foscue HA and Shelburne J: Structural and biochemical changes in rat lungs occurring during exposures to lethal and adaptive dose of oxygen. Am Rev Respir Dis 122: 123-143, 1980.

3. Reddy GP: Cell cycle: Regulatory events in G1->S transition of mammalian cells. J Cell Biochem 54: 379-386, 1994.

4. Al-Khalaf HH, Colak D, Al-Saif M, Al-Bakheet A, Hendrayani SF, Al-Yousef N, Kaya N, Khabar KS and Aboussekhra A: p16(INK4a) positively regulates cyclin D1 and E2F1 through negative control of AUF1. PLoS One 6: e21111, 2011.

5. Vogelstein B and Kinzler KW: Cancer genes and the pathways they control. Nat Med 10: 789-799, 2004. 
6. Haller F, Löbke C, Ruschhaupt M, Cameron S, Schulten HJ, Schwager S, von Heydebreck A, Gunawan B, Langer C, Ramadori G, et al: Loss of 9p leads to p16(INK4A) down-regulation and enables RB/E2F1-dependent cell cycle promotion in gastrointestinal stromal tumours (GISTs). J Pathol 215: 253-262, 2008.

7. Wu Z and Yu Q: E2F1-mediated apoptosis as a target of cancer therapy. Curr Mol Pharmacol 2: 149-160, 2009.

8. Giacinti $\mathrm{C}$ and Giordano A: RB and cell cycle progression. Oncogene 25: 5220-5227, 2006.

9. Tyagi E, Liu B, Li C, Liu T and Rutter J and Grossman D: Loss of p16 INK4A stimulates aberrant mitochondrial biogenesis through a CDK4/Rb-independent pathway. Oncotarget 8: 55848-55862, 2017.

10. Zhao SM, Wu HM, Cao ML and Hna D: Primary culture of lung fibroblasts from hyperoxia-exposed rats and a proliferative characteristics study. Cytotechnology 70: 751-760, 2018.

11. Zhao S, Cao M, Wu H, Hu Y and Xue X: 5-aza-2'-deoxycytidine inhibits the proliferation of lung fibroblasts in neonatal rats exposed to hyperoxia. Pediatr Neonatol 58: 122-127, 2017.

12. Chen $X$, Zhang $X$ and Pan J: Effect of montelukast on bronchopulmonary dysplasia (BPD) and related mechanisms. Med Sci Monit 25: 1886-1893, 2019.

13. Qi XJ, Ning W, Xu F, Dang HX, Fang F and Li J: Fasudil, an inhibitor of Rho-associated coiled-coil kinase, attenuates hyperoxia-induced pulmonary fibrosis in neonatal rats. Int J Clin Exp Pathol 8: 12140-12150, 2015.

14. $\mathrm{Hu} \mathrm{Y}, \mathrm{Fu} \mathrm{J}$ and Xue X: Association of the proliferation of lung fibroblasts with the ERK1/2 signaling pathway in neonatal rats with hyperoxia-induced lung fibrosis. Exp Ther Med 17: 701-708, 2019.

15. Herman JG, Graff JR, Myohanen S, Nelkin BD and Baylin SB: Methylation specific PCR: A novel PCR assay for methylation status of CpG islands. Proc Natl Acad Sci USA 93: 9821-9826, 1996.

16. Huang Y, Wu G, Fan H, Ye J and Liu X: Electroacupuncture promotes chondrocyte proliferation via accelerated G1/S transition in the cell cycle. Int JMol Med 31: 1443-1448, 2013.

17. Sharpless NE and DePinho RA: The INK4A/ARF locus and its two gene products. Curr Opin Genet Dev 9: 22-30, 1999.

18. Williams RT, Barnhill LM, Kuo HH, Lin WD, Batova A, Yu AL and Diccianni MB: Chimeras of p14ARF and p16: Functional hybrids with the ability to arrest growth. PLoS One 9: e88219, 2014

19. Gil J and Peters G: Regulation of the INK4b-ARF-INK4a tumour suppressor locus: All for one or one for all. Nat Rev Mol Cell Biol 7: 667-677, 2006.

20. Sharpless NE: INK4a/ARF: A multifunctional tumor suppressor locus. Mutat Res 576: 22-38, 2005.

21. Yue X, Fu J, Xue X, Gao H, Liu D, Zong Z, Wang W and Yuan Z: Detection of p16 promoter methylation in premature rats with chronic lung disease induced by hyperoxia. Pediatr Int 52 : $520-526,2010$
22. Rayess H, Wang MB and Srivatsan ES: Cellular senescence and tumor suppressor gene p16. Int J Cancer 130: 1715-1725, 2012.

23. Thompson JF, Scolyer RA and Kefford RF: Cutaneous melanoma. Lancet 365: 687-701, 2005.

24. Myong NH: Cyclin D1 overexpression, p16 loss, and pRb inactivation play a key role in pulmonary carcinogenesis and have a prognostic implication for the long-term survival in non-small cell lung carcinoma patients. Cancer Res Treat 40: 45-52, 2008.

25. Dobashi Y, Goto A, Fukayama M, Abe A and Ooi A: Overexpression of cdk4/cyclin D1, a possible mediator of apoptosis and an indicator of prognosis in human primary lung carcinoma. Int J Cancer 110: 532-541, 2004.

26. Mittnacht S: The retinoblastoma protein-from bench to bedside. Eur J Cell Biol 84: 97-107, 2005.

27. Wang X,Huang K and Xu LN: Interaction among Rb/p16, Rb/E2F1 and $\mathrm{HDACl}$ proteins in gallbladder carcinoma. J Huazhong Univ Sci Technolog Med Sci 29: 729-731, 2009.

28. Haluska FG, Tsao H, Wu H, Haluska FS, Lazar A and Goel V: Genetic alterations in signaling pathways in melanoma. Clin Cancer Res 12: 2301s-2307s, 2006.

29. Palmieri G, Capone M, Ascierto ML, Gentilcore G, Stroncek DF, Casula M, Sini MC, Palla M, Mozzillo N and Ascierto PA: Main roads to melanoma. J Transl Med 7: 86, 2009.

30. Wikman H and Kettunen E: Regulation of the G1/S phase of the cell cycle and alterations in the RB pathway in human lung cancer. Expert Rev Anticancer Ther 6: 515-530, 2006.

31. Thomas NS, Pizzey AR, Tiwari S, Williams CD and Yang J: $\mathrm{p} 130, \mathrm{p} 107$, and $\mathrm{pRb}$ are differentially regulated in proliferating cells and during cell cycle arrest by alpha-interferon. J Biol Chem 273: 23659-23667, 1998.

32. Clijsters L, Hoencamp C, Calis JJA, Marzio A, Handgraaf SM, Cuitino MC, Rosenberg BR, Leone G and Pagano M: Cyclin F controls cell-cycle transcriptional outputs by directing the degradation of the three activatorE2Fs. Mol Cell 74: 1264-1277.e7, 2019.

33. Stanelle J, Stiewe T, Theseling CC, Peter M and Pützer BM: Gene expression changes in response to E2F1 activition. Nucleic Acides Res 30: 1859-1867, 2002

34. Han S, Park K, Bae BN, Kim KH, Kim HJ, Kim YD and Kim HY: E2F1expression is related with the poor survival of lymph node-positive breast cancer patients treated with fluorouracil, doxorubicin and cyclophosphamide. Breast Cancer Res Treat 82: 11-16, 2003.

35. Eymin B, Gazzeri S, Brambilla C and Brambilla E: Distinct pattern of E2F1 expression in human lung tumours: E2F1 is upregulated in small cell lung carcinomal. Oncogene 20: 1678-1687, 2001. 